\title{
ESTUDO COMPARATIVO DA TERMOESTABILIDADE DE ENZIMAS PRODUZIDAS POR FUNGOS FILAMENTOSOS EM CULTIVO SUBMERSO E COMBINADO
}

\author{
V. M. VASCONCELLOS ${ }^{1,3}$, C.FLORENCIO ${ }^{2,3}$, A. C. BADINO ${ }^{1,2}$, R. L. C. GIORDANO ${ }^{1}$, P. W. \\ TARDIOLI ${ }^{1}$ e C. S. FARINAS ${ }^{1,2,3}$ \\ ${ }^{1}$ Universidade Federal de São Carlos, Departamento de Engenharia Química \\ ${ }^{2}$ Universidade Federal de São Carlos, Programa de Pós-Graduação em Biotecnologia \\ ${ }^{3}$ Embrapa Instrumentação, Laboratório de Agroenergia, São Carlos \\ E-mail para contato: vanessamolina_10@yahoo.com.br
}

\begin{abstract}
RESUMO - A termoestabilidade é uma das características que influenciam a eficiência dos complexos enzimáticos, sendo o parâmetro tempo de meia vida utilizado para avaliar tal propriedade. Celulases e xilanases termoestáveis apresentam vantagens na aplicação industrial.Neste trabalho comparou-se a termoestabilidade de extratos enzimáticos produzidos por dois métodos de cultivos (submerso e combinado) e três linhagens fúngicas (Aspergillus niger, Trichoderma harzianum e Trichoderma sp INPA 666), possibilitando a determinação do tempo de meia vida para as enzimas endoglucanases e xilanases a $50^{\circ} \mathrm{C}$. Os tempos de meia vida obtidos diferiram entre si quanto ao método de cultivo e fungo. Para endoglucanases, os extratos do cultivo submerso se mostraram mais termoestáveis, destacando-se o extrato do A. niger com o tempo de meia vida de 156 min. Para xilanases, o cultivo combinado do T. harzianum resultou em uma maior termoestabilidade, com tempo de meia vida de 383 min.
\end{abstract}

\section{INTRODUÇÃO}

O etanol de segunda geração, ou etanol 2G, produzido a partir da biomassa lignocelulósica tem ganhado reconhecimento como uma alternativa promissorade energia renovável e sustentável. Contudo,o desenvolvimento da produção do etanol $2 \mathrm{G}$ enfrenta algumas dificuldades técnicas a serem superadas como a recalcitrância da biomassa para hidrólise e o alto custo das celulases, enzimas necessárias para a conversão da biomassa(Farinas et al., 2010).

A biomassa lignocelulósica é constituída por polímeros de celulose e hemicelulose entrelaçados e ligados covalentemente a lignina que podem ser hidrolisados em monômeros de glicose, utilizada como substrato para a fermentação alcóolica (Pereira Jr., 2006). Para isso, a matéria-prima é hidrolisada por um complexo enzimático constituído por três classes principais de enzimas:as endoglucanases, as exoglucanases e as $\beta$-glicosidases, que atuamsinergicamente(Zhanget al., 2006). As xilanases atuam como enzimas acessórias, desestruturando o entrelaçamento da hemicelulose presente na parede vegetal, facilitando o 


\section{9 a 22 de outubro de 2014 \\ Florianópolis/SC}

acesso à celulose(Dodd e Cann, 2009).A aplicação de xilanases em conjunto com enzimas celulolíticas tem sido amplamente considerado para a bioconversão de materiais lignocelulósicos(Pirota et al., 2013).

Fungos filamentosos são capazes de produzir diferentes coquetéis enzimáticos.As espécies de Aspergillus, quando em contato com biomassas lignocelulósicas, produzem uma grande variedade de enzimas para a degradação do material (Kang et al., 2004).A espécieA. niger destaca-se com a produção de um complexo enzimático contendo celulases, xilanases e outras enzimas acessórias e seucomplexo enzimático é considerado termoestável (Farinas et al., 2010).OT.reesei é o fungo celulolítico melhor caracterizado e o mais utilizado industrialmente para a produção de celulases e hemicelulases (King et al., 2009)e é considerado como um produtor em potencial de celulases.A pesquisa com fungos do gênero Trichoderma é hoje em dia focada no aumento da eficiência da produção do coquetel enzimático, com a finalidade de reduzir os custos totais na produção de bioetanol a partir de materiais celulósicos (Kumar et al., 2008).

O complexo enzimático celulolítico pode ser produzido por diferentes bioprocessos. A fermentação em estado sólido (FES) é caracterizada pelo cultivo em substrato sólido e é conduzida com umidade controlada, enquanto a fermentação submersa (FSm) ocorre em meio líquido, sendo os dois processos ditos convencionais. Um terceiro processo é a fermentação combinada (FC) desenvolvida por Cunha et al. (2012) e caracteriza-se pela elaboração de um précultivo com etapa inicial no estadosólido e posterior transição para cultivo submerso.

As condições de produção e aplicação das celulases possuem condições operacionais distintas, podendo ser simultâneos ou não, dessa forma as enzimas necessitam cumprir requisitos especiaisem termos de $\mathrm{pH}$ e temperatura ótimos, alémda estabilidade térmica (Farinas et al., 2010). Em processos de hidrólise, as enzimas termoestáveis apresentam várias vantagens, como atividade específica mais elevada, oque ocasiona a diminuiçãona quantidade da carga enzimática no processo, maior estabilidade alongando o tempo de hidrólise e permitindo oaumentoda flexibilidade de variações no processo (Viikariet al., 2007).

A escolha do microrganismo e das condições de cultivo (inóculo, meio de cultura, condições operacionais, indutores) podem impactar na morfologia de crescimento do microrganismo, e consequentemente, em diferentes padrões de expressão gênica e secreção de proteínas (Holker et al., 2004). Dessa forma, os extratos enzimáticos podem variar quantitativa e qualitativamente.

Neste contexto, o presente trabalho avaliou a influência do uso de diferentes fungos filamentosos (A. niger, $T$. harzianum e $T$. sp INPA 666)e de diferentes formas de cultivo (cultivo submerso e combinado) nacomposição enzimáticados extratos produzidos e suas característicasem termos da estabilidade térmica. O substrato indutorutilizado foi bagaço de canade açúcar pré-tratado por explosão a vapor.

\section{MATERIAIS E MÉTODOS}




\subsection{Microrganismos}

Os agentes fermentadoresutilizados foram os fungos filamentosos Aspergillus niger 3T5B8, Trichoderma harzianumP49P11 e Trichoderma sp INPA 666, pertencentes à coleção de culturas da Embrapa Agroindústria de Alimentos, Embrapa Instrumentação e Embrapa Agroindustrial Tropical, respectivamente. Os conídiosforam mantidos sob congelamento em glicerol $20 \%$ a $-18^{\circ} \mathrm{C}$ e ativados em meio de cultivo batata dextrose ágar (BDA) a $32^{\circ} \mathrm{C}$ durante cinco dias para o A. niger, e $30^{\circ} \mathrm{C}$ durante sete dias para as duas linhagens de Trichoderma.

\subsection{Matéria-Prima Lignocelulósica}

A matéria-prima lignocelulósica indutora utilizada foi o bagaço de cana-de-açúcar prétratado por explosão a vapor (BEX). O material seco foi selecionado por peneiramento na faixa granulométrica $1,00 \leq \mathrm{X} \leq 2,00 \mathrm{~mm}$.

\subsection{Condições dePré-Cultivo}

Os procedimentos descritos envolvendo as condições de cultivo e a produção enzimática foram realizados para cada microrganismo.

Meio de cultivo: O meio de cultivo utilizado foi o meio descrito por Mandels andSternberg (1976), adaptado por Cunha et al. (2012).

Procedimento de pré-cultivo submerso (FSm): no método de fermentação submersa (ou convencional) os esporos ativados em BDA foram ressuspendidos e inoculados diretamente em meio líquido. Nesse procedimento, foram inoculados $10^{7}$ esporos $/ \mathrm{mL}$ de meio de cultivo, enriquecidos por $30 \mathrm{~g} / \mathrm{L}$ de glicose e $\mathrm{pH}$ inicial 4,5. Essa etapa foi conduzida em mesa incubadora rotativa a $200 \mathrm{rpm}$ e na temperatura ideal para cada microrganismo descrito na secção 2.1, por aproximadamente 48 horas, o tempo necessário para a germinação dos esporos.

Procedimento de pré-cultivo combinado (FC): este tipo de pré-cultivo foi conduzido em duas etapas. A primeira etapa foi realizada em estado sólido, na qual $10^{7}$ esporos/g de substrato sólido foram inoculados diretamente no BEX.A umidade do indutor foi ajustada para $60 \%$ com a adição do meio de cultivo, sem a suplementação de glicose.Os frascos permaneceram incubados em estufa na temperatura ideal para cada microrganismo descrito na secção 2.1por 24h. Após esse período iniciou-se a segunda etapa, que consistiu na transição dos pré-cultivos para a fermentação submersa através da adição de meio líquido enriquecido com $30 \mathrm{~g} / \mathrm{L}$ de glicose e pH inicial 6,0. Os fracos foram mantidos em mesa incubadora rotativa a $200 \mathrm{rpm}$ na temperatura ideal para cada microrganismo descrito na secção 2.1 por 48h (Cunha et al.,2012).

\subsection{Produção Enzimática}

A produção enzimática foi realizada em frascos Erlenmeyer contendo $100 \mathrm{~mL}$ de volume útil, composto pelo meio de cultivo descrito na secção 2.3 enriquecido com $10 \mathrm{~g} / \mathrm{L}$ de glicose, $1 \%$ 
$(\mathrm{m} / \mathrm{v})$ de BEX e inoculados com $10 \%$ (v/v) do caldo do pré-cultivo. Os fracos foram mantidos em mesa incubadora rotativa a $200 \mathrm{rpm}$ por $72 \mathrm{~h}$ na temperatura ideal para cada microrganismo (secção 2.1). No final das $72 \mathrm{~h}$ as amostras foram filtradas e centrifugadas a $11000 \mathrm{rpm}$ por 15 min a $4^{\circ} \mathrm{C}$ e mantidas sob congelamento para posteriores análises.

\subsection{Procedimento Analítico}

Atividade de endoglucanase: a atividade de endoglucanase foi determinada a $50^{\circ} \mathrm{C}$, tendo como substrato a solução de carboximetilcelulose (CMC) 0,4\% em tampão citrato de sódio 0,2M, $\mathrm{pH} 4,8$, por 10 minutos à $50^{\circ} \mathrm{C}$ de acordo com adaptações feitas na metodologia de Ghose (1987).

Atividade de xilanase: a atividade de xilanase foi determinada utilizando-se como substrato uma solução de xilana $1 \%$ em tampão acetato de sódio $0,2 \mathrm{M}$, pH 5,0, por 5 minutos à $50^{\circ} \mathrm{C}$, adaptado de Bailey e Poutanen (1989).

Uma unidade de atividade enzimática (UI) corresponde a $1 \mu$ mol de grupos redutores liberados por minuto de reação. Os açúcares liberados foram determinados pelo método de DNS segundo Miller (1959).

Estabilidade Térmica: para os ensaios de estabilidade térmica o complexo enzimático permaneceu incubado em condições estáticas, em banho termostatizado à $50^{\circ} \mathrm{C}$ por 24 horas. As alíquotas foram retiradas após 10, 60, 120, 240, 360, 480, 720 e 1440 minutos, e imediatamente resfriadas em banho de gelo para interromper a reação de inativação e analisadas de acordo com os procedimentos de atividades descrito na secção 2.4. Os dados foram ajustados utilizando um modelo exponencial não-linear de Sadana e Henley (1987).A partir da Equação (1) foi possível calcular a constante de inativação térmica, na qual $A r$ é a atividade relativa (adimensional), $\alpha$ é a relação entre a atividade específica no estado final e inicial, $k_{d}$ é a constante de inativação térmica de primeira ordem $\left(\mathrm{min}^{-1}\right)$ e $t$ é o tempo de incubação da solução enzimática (min). O tempo de meia vida foi definido como o tempo necessário para que ocorra uma redução de $50 \%$ da atividade inicial.

$$
A r=(1-\alpha) * \exp \left(-k_{d} * t\right)+\alpha
$$

\section{RESULTADOS E DISCUSSÃO}

O cultivo submerso (FSm) e o cultivo combinado (FC) com os fungos A. niger, T. harzianum, e T. sp foramconduzidos a fim de avaliar a influência da metodologia de cultivo e da linhagem do microrganismona produção enzimática. Quantitativamente, avaliou-se a atividade da endoglucanase e da xilanases e, qualitativamente, a estabilidade térmica à $50{ }^{\circ} \mathrm{C}$, temperatura na qual as enzimas apresentam maior desempenho e a hidrólise da biomassa lignocelulósica se processa.

A Figura 1mostra o comportamento da termoestabilidade dos extratos enzimáticos para atividade de endoglucanase em função do tempo de incubação.Todos os coquetéis enzimáticos se 
ajustaram ao modelo escolhido edesse modo pôde-se determinar o tempo de meia vida das endoglucanases.Os dados para os extratos obtidos pela linhagem do $T$. sp, naFSm e FC, e a linhagem $T$. harzianum, naFC, foram os que melhores se ajustaram ao modelo exponencial não linear para essa classe enzimática.O comportamento dos extratos enzimáticos para atividade da enzima xilanase também foi avaliado com o decorrer do período de incubação (Figura 1).O extrato combinado do fungo $T$. sp INPA 666 foi o que menos se ajustouao modelo de Sadana e Henley (1987), porém foi possível para todas as linhagens determinaro tempo de meia vida.
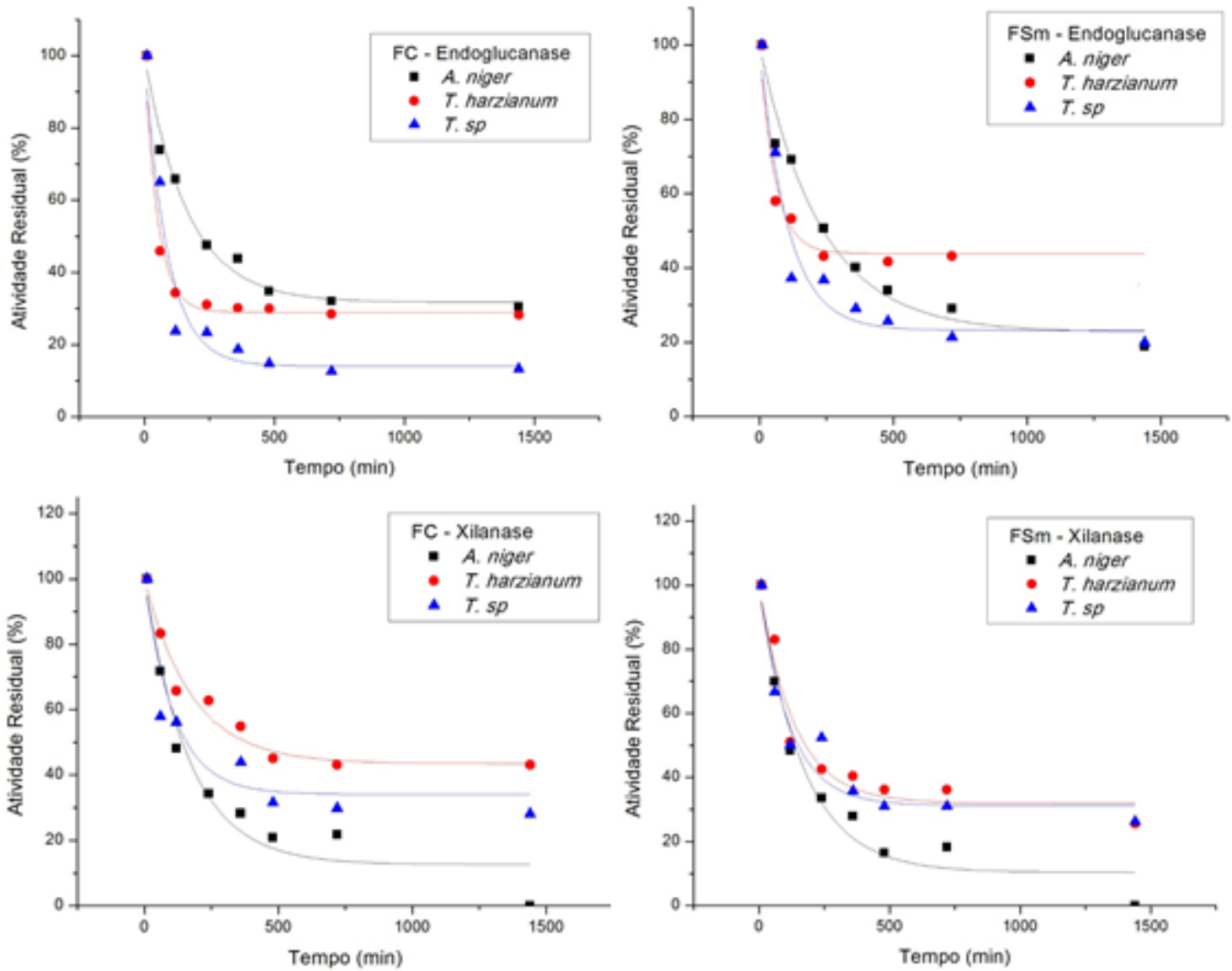

Figura 1 - Atividade residualde endoglucanase e xilanase para os cultivos submerso (FSm) e combinado (FC), os extratos foram incubados a $50^{\circ} \mathrm{C}$ por $1440 \mathrm{~min}$.

A Tabela 1 apresenta os resultados endoglucanasedos parâmetrosestimados, tempo de meia vida $\left(\mathrm{t}_{1 / 2}\right)$ em minutos e a atividade enzimática (UI.L $\left.{ }^{-1}\right)$ antes do início da inativação térmica por incubação a $50^{\circ} \mathrm{C}$. Para as duas linhagens de Trichodermao cultivo por FC influenciou positivamente na produção enzimática, masdiminuiu a estabilidade térmica, como pode ser observado pelos valores do tempo de meia vida.O fungo $T$. harzianum destacou-se com a resposta mais expressiva com relação às técnicas de cultivo.O tempo de meia vida, na FSm, e a atividadeenzimática, na FC, foram aproximadamente 2 vezes maiores para o T. harzianum em 
comparaçãocom as enzimas produzidas pelas outras linhagens avaliadas.

Para a classe das endoglucanases dos extratos analisados, a maior atividade e viabilidade térmica enzimática não ocorrem simultaneamente.O extrato do A. niger produzido através da FSmapresentou o maior tempo de meia vida (156 min), contudo esse extrato apresentou a menor atividade enzimática (576 UI.L $\left.{ }^{-1}\right)$. $\mathrm{O}$ maiorvalor de atividade para endoglucanase encontrado(1668 UI/L ${ }^{-1}$ ) relaciona-se com o menor tempo de meia vida (62 min), oriundos da FC utilizando a linhagem $T$. harzianum.

Segundo Farinas et al. (2010), as endoglucanases presentes no extrato de uma linhagem de $A$. niger em FES, incubados nas mesmas condições experimentais desse estudo, apresentouo tempo de meia vida de 2598 minutos, esses resultados foram semelhantes aos de Soni et al. (2010), estimou que as endoglucanases produzidas por Aspergillusspem FES retinham 66\% da estabilidade após 4320 minde incubação. De acordo com Busto et al. (1996) endoglucanases produzidas por uma linhagem de T.Reesei, em FSm, apresentou um tempo de meia vida de 564 e 252 minà 55 e $60^{\circ} \mathrm{C}$, respectivamente.Assim as enzimas produzidas em FES são mais termoestáveis do que as produzidas por FSm e FC.

Tabela 1 - Tempo de meia vida e atividade inicial das enzimas endoglucanases produzidas por dois métodos de cultivo e diferentes linhagens de fungos filamentosos.

\begin{tabular}{ccccccc}
\hline \multirow{2}{*}{ Fungo } & Cultivo & $\mathbf{R}$ & $\boldsymbol{\alpha}$ & $\begin{array}{c}\mathbf{K}_{\mathbf{d}} \\
\left(\mathbf{m i n}^{-\mathbf{1}}\right)\end{array}$ & $\begin{array}{c}\text { Tempo de } \\
\text { meia vida } \\
(\mathbf{m i n})\end{array}$ & $\begin{array}{c}\text { Atividade } \\
\text { Inicial } \\
\left(\mathbf{U I . L}^{-1}\right)\end{array}$ \\
\cline { 3 - 7 } A. niger & FSm & 0,86 & 0,143 & 0,00561 & 156 & 577 \\
& FC & 0,86 & 0,288 & 0,01071 & 113 & 575 \\
\hline \multirow{2}{*}{ T. harzianum } & FSm & 0,85 & 0,439 & 0,01751 & 126 & 769 \\
& FC & 0,95 & 0,289 & 0,01959 & 62 & 1668 \\
\hline \multirow{2}{*}{ Trichodermasp } & FSm & 0,95 & 0,232 & 0,00953 & 110 & 619 \\
& FC & 0,95 & 0,140 & 0,01131 & 77 & 833 \\
\hline
\end{tabular}

Assim como para a endoglucanase, a Tabela 2 apresentaos resultados dos parâmetros estimados, tempo de meia vida $\left(\mathrm{t}_{1 / 2}\right)$ em minutos e a atividade enzimática (UI.L ${ }^{-1}$ ) antes do início da inativação térmica por incubação a $50^{\circ} \mathrm{C}$ para a enzima xilanase. A linhagem T. harzianum destacou-se novamente com umaumento expressivo de valores a partir da mudança da técnica de cultivo, tanto para atividade enzimática quanto para a estabilidade das enzimas.O fungo $T$. harzianum apresentou o melhor tempo de meia vida (383 min)para as xilanases produzidas a partir da FC. O perfil das xilanases foi semelhante aos das endoglucanases.O coquetel enzimático com maior valor em relação à atividade $\left(6030 \mathrm{UI} / \mathrm{L}^{-1}\right)$ foi o mais instável termicamente, apresentando um tempo de meia vida de $56 \mathrm{~min}$, sendo esse extrato produzido pelofungo A. niger no cultivo combinado.

Tabela 2 - Tempo de meia vida e atividade inicial das enzimas xilanases produzidas por dois métodos de cultivo e diferentes linhagens de fungos filamentosos. 


\begin{tabular}{ccccccc}
\hline \multirow{2}{*}{ Fungo } & Cultivo & $\mathbf{R}$ & $\boldsymbol{\alpha}$ & $\begin{array}{c}\mathbf{K}_{\mathbf{d}} \\
\left(\mathbf{m i n}^{-\mathbf{1}}\right)\end{array}$ & $\begin{array}{c}\text { Tempo de } \\
\text { meia vida } \\
(\mathbf{m i n})\end{array}$ & $\begin{array}{c}\text { Atividade } \\
\text { Inicial } \\
\left(\mathbf{U I . L}^{-\mathbf{1}}\right)\end{array}$ \\
\cline { 3 - 7 } A. niger & FSm & 0,89 & 0,155 & 0,01580 & 57 & 4913 \\
& FC & 0,89 & 0,179 & 0,01685 & 56 & 6030 \\
\hline \multirow{2}{*}{ T. harzianum } & FSm & 0,94 & 0,320 & 0,00745 & 179 & 1407 \\
& FC & 0,96 & 0,435 & 0,00564 & 383 & 3054 \\
\hline \multirow{2}{*}{ T. sp } & FSm & 0,92 & 0,312 & 0,00862 & 151 & 1258 \\
& FC & 0,83 & 0,341 & 0,00900 & 158 & 1706 \\
\hline
\end{tabular}

Para as xilanases, Farinas et al. (2010) determinaram o tempo de meia vida de5400 min dessas enzimas presentes no extrato de uma linhagem de A. niger em FES, incubadas as $50^{\circ} \mathrm{C}$. Shad e Madamwar (2005) verificaram que xilanases produzidas pela linhagem A. foetidus em FSm mantinham apenas $36 \%$ de sua ativade após 180min.Castroet al. (1997) avaliaram atermoestabilidade dasxilanasesproduzidasporumaestirpe de Aspergillustermotolerante em FSm, na ausência de substratoossistemas analisados mantinham50\% e30\% da sua atividadedepois de30mindeincubação $a 50^{\circ} \mathrm{C}$.

Os resultados encontrados na literatura corroboram com o do presente trabalho, indicando que a técnica de cultivo e microrganismo produtor realmente influenciamna estabilidade e atividade enzimática. Observou-se ainda que a classe enzimática das endoglucanases apresenta um maior tempo de meia vida em relação as xilanases.Assim,ao escolher o extrato enzimático que será utilizado na hidrólise do material lignocelulósico deve-se analisar previamente a sua atividade enzimática e estabilidade térmica.

\section{CONCLUSÃO}

A estabilidade térmica enzimática foi influenciada tanto pela técnica de cultivo quanto pelo microrganismo utilizado para a produção das enzimas.Para as endoglucanases, os extratos do cultivo submerso se mostraram mais termoestáveis, destacando-se o extrato do A. niger com o tempo de meia vida de 156 min.Para xilanases, o cultivo combinado do T. harzianum resultou em uma maior termoestabilidade, com tempo de meia vida de 383 min.Entretanto, a maior atividade e viabilidade térmica enzimática não ocorrem simultaneamente tanto para as endoglucanases, quanto para as xilanases.

\section{REFERÊNCIAS}

BAILEY, M.J.; POUTANEN, K.; Production of xylanolytic enzymes by strains of Aspergillus. Appl Microbiol Biotechnol, n.30, p.5-10, 1989.

BUSTO, M. D.; ORTEGA, N.; PEREZ-MATEOS. Location, kinetics and stability of cellulasesinduced in Trichoderma reesei cultures. Bioresource Technol, n. 57, p. 187-192, 1996 CASTRO, L. P. M.; TREJO-AGUILAR, B. A.; OSORIO, G. A. Thermostable xylanases produced at $37^{\circ} \mathrm{C}$ and $45^{\circ} \mathrm{C}$ by a thermotolerant Aspergillus strain. Fems Microbiol. Lett. 146, 97-102, 1997 

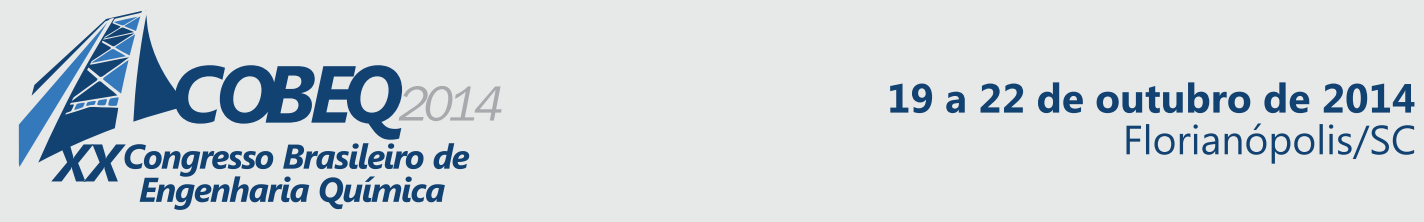

CUNHA, F.M.; BACCHIN, A.L.G.; HORTA, A.C.L.; ZANGIROLAMI, T.C.; BADINO, A.C.; FARINAS, C.S. Indirect method for quantification of cellular biomass in a solidscontaining medium used as pre-culture for cellulase production. Biotechnol Bioproc Eng. N. 17, p. 100-108, 2012.

DODD, D.; CANN, I. Enzymatic deconstruction of xylan for biofuel production.Glob. Change Biol. Bioenergy, 1, 2-17. 2009.

FARINAS, C. S.; LOYO, M. M.; BERALDO Jr. A.; TARDIOLI, P. W.; NETO, V. B.; COURI, $\mathrm{S}$. Finding stable cellulase and xylanase evaluation of the synergistic effect of $\mathrm{pH}$ and temperature. New Biotechnol, v. 27, n. 6, p. 810-815, Dec 2010.

GHOSE, T.K. Measurement of cellulase activies. Pure \& Appl Chem, Oxford, v.59, n.2, p. 257268, 1987.

HÖLKER, U, HÖFER, M., LENZ, J. Biotechnological advantages of laboratory-scale solidstate fermentation with fungi. Appl. Microbiol. Biotechnol. n.64, p. 175-186, 2004.

KANG, S.W.; PARK, Y.S.; LEE, J.S.; HONG, S.I. and KIM, S.W. Production of cellulases and hemicellulases by Aspergillus niger KK2 from lignocellulosic biomass. Bioresour. technol, v. 91, n. 2, p. 153-156, Jan 2004.

KING, B.C.; DONNELLY, M. K,; BERGSTROM, G. C.; WALKER, L. P.; GIBSON, D. M.. An Optimized Microplate Assay System for Quantitative Evaluation of Plant Cell Wall-Degrading Enzyme Activity of Fungal Culture Extracts. Biotechnol Bioeng, 102: 1033-1044, 2009

KUMAR, R.; SINGH, S.; SINGH, O. V; Bioconversion of lignocellulosic biomass: biochemical and molecular perspectives. J Ind Microbiol Biot, 35: 377-391, 2008

MANDELS, M.; STERNBERG, D. Recent advances in cellulase technology. Fermentation Technol. n.54, p.256-286, 1976.

MILLER, G.L. Use of dinitrosalicilic acid reagent for determination of reducing sugar. Anal. Biochem., v. 31, p. 426-428, 1959.

PEREIRA JR, N. Biotecnologia de materiais lignocelulósicos para a produção química. Escola de Química. Universidade Federal do Rio de Janeiro..In: 11 Encontro Anual da Indústria Química. Prêmio Abiquim de Tecnologia 2006, São Paulo, 2006.

PIROTA, R. D. P. B.; TONELOTTO, M.; DELABONA P. da S.; FONSECA, R.F.; PAIXÃO, D. A. A.; BALEEIRO, F. C. F.; NETO, V. B.; FARINAS, C. S. Enhancing xylanases production by a new Amazon Forest strain of Aspergillus oryzae using solid-state fermentation under controlled operation conditions. Ind Crop Prod, 45: 465-471, 2013

SADANA, A.; HENLEY, J. P. Single-step unimolecular non-first-order enzyme deactivation kinetics. Biotechnol Bioeng, v. 30, p. 717-723, 1987.

SHAH, A.R.; MADAMWAR, D. Xylanase production by a newly isolatedAspergillus foetidus strain and its characterization. Process Biochem, 40, 1763-177, 2005.

SONI, S. K.; BATRA, N.; BANSAL, N.; SONI, R. Bioconversion of sugarcane bagasse into second generation bioethanol after enzymatic hydrolysis with in-house produced cellulases from Aspergillus sp, S4B2F. BioRes. 5, 741-757, 2010.

VIIKARI, L.; ALAPURANEN, M.; PURANEN, T.; VEHMAANPERA, J.; SIIKA-AHO, M.Thermostable enzymes in lignocellulose hydrolysis. Adv. Biochem. Eng. Biotechnol,v. 108, p. 121-145, 2007.

ZHANG, Y-H.P.; HIMMEL, M. E.; MIELENZ,J. R. Outlook for cellulase improvement: screening and selection strategies. Biotechnol. adv. v.24, p.452-481, 2006. 